\title{
Obesity Paradox in Peripheral Arterial Disease: Results of a Propensity Match Analysis from the National Inpatient Sample
}

Dipesh Ludhwani ${ }^{1}$, Joyce $\mathrm{Wu}^{2}$

1. Internal Medicine, Rosalind Franklin University of Medicine and Science, North Chicago, USA 2. Biostatistics, University of Michigan, Ann Arbor, USA

$\square$ Corresponding author: Dipesh Ludhwani, dipeshludhwani91@gmail.com Disclosures can be found in Additional Information at the end of the article

\section{Abstract}

\section{Introduction}

The role of obesity in cardiovascular mortality is controversial. The obesity paradox has been widely attributed to smoking in the underweight. Large-scale studies analyzing the outcomes of peripheral arterial disease (PAD) in patients with a higher body mass index (BMI) while accounting for confounders such as smoking are lacking.

\section{Method}

The 2016 National Inpatient Sample (NIS) was used to identify all admissions with a primary discharge diagnosis of PAD. A secondary diagnosis of obesity or elevated BMI was used to segregate the admissions into two groups. Propensity scores were calculated to match and control both groups for age, smoking, and diabetes, amongst other confounders. A multivariate logistic and linear regression analysis was performed to calculate the odds ratio for in-hospital mortality, amputation, need for intervention (angioplasty or bypass), acute kidney injury, hospital charges, and length of stay. Non-obesity-related PAD admissions were selected as the reference groups.

\section{Results}

Among 248,288 PAD-related admissions, 41,618 had a secondary diagnosis of obesity. After calculating propensity scores for 1-1 matching, 41,589 admissions in the PAD and obesity group were compared to a similar number of admissions in the reference population. Patients with a concomitant diagnosis of obesity had lower odds of amputation (OR=0.90, 95\% CI=0.84-0.95,

Received 05/14/2019 Review began 05/16/2019 Review ended 05/17/2019 Published 05/21/2019

\section{(c) Copyright 2019}

Ludhwani et al. This is an open access article distributed under the terms of the Creative Commons Attribution License CC-BY 3.0., which permits unrestricted use, distribution, and reproduction in any medium, provided the original author and source are credited. $\mathrm{p}<0.001)$, need for intervention $(\mathrm{OR}=0.66,95 \% \mathrm{CI}=0.62-0.69, \mathrm{p}<0.0001)$, and in-hospital mortality $(\mathrm{OR}=0.81,95 \% \mathrm{CI}=0.74-0.87, \mathrm{p}<0.0001)$. On the contrary, the odds of having acute kidney injury were higher with elevated $\mathrm{BMI}(\mathrm{OR}=1.30,95 \% \mathrm{CI}=1.26-1.34, \mathrm{p}<0.0001)$.

\section{Conclusion}

Despite increasing the risk of hypertension, diabetes, and hypertriglyceridemia, the obesity paradox continues to exist with a better short-term prognosis in patients with PAD. Future studies looking into the pathophysiology behind this phenomenon are needed. 
Categories: Cardiology, Internal Medicine, Preventive Medicine

Keywords: national inpatient sample, obesity, obesity paradox, peripheral artery disease, propensity match, body mass index

\section{Introduction}

Over the last few decades, obesity has emerged as a global epidemic with its prevalence constantly on the rise [1]. The role of body mass index (BMI) as a surrogate marker in defining and quantifying the degree or severity of obesity has been well-established in numerous epidemiological studies. Formally defined as a BMI of $30.0 \mathrm{~kg} / \mathrm{m}^{2}$ or higher, obesity has been a significant cause of morbidity and mortality worldwide. Obesity is further stratified as class I (30 kg/m $\mathrm{m}^{2}$ to $\left.34.9 \mathrm{~kg} / \mathrm{m}^{2}\right)$, class II $\left(35 \mathrm{~kg} / \mathrm{m}^{2}\right.$ to $\left.39.9 \mathrm{~kg} / \mathrm{m}^{2}\right)$, and class III, also known as severe or morbid obesity $\left(>40 \mathrm{~kg} / \mathrm{m}^{2}\right)$. The term 'overweight,' which is usually reserved for BMI between $25.0 \mathrm{~kg} / \mathrm{m}^{2}$ and $29.9 \mathrm{~kg} / \mathrm{m}^{2}$ is also associated with increased all-cause mortality [2-3]. The holistic impact of obesity was reflected in a report that concluded a potential decline in life expectancy due to the former's hazardous effects on body homeostasis [4]. Obesity poses a significant health care burden to society and has been directly linked with the risks of diabetes mellitus, hypertension, dyslipidemia, cardiovascular disease, stroke, venous thrombosis, musculoskeletal complications, gastroesophageal reflux disease, and malignancy [5-7]. BMIrelated mortality follows either a J-shaped or a U-shaped curve, with the lowest mortality close to a BMI of $25 \mathrm{~kg} / \mathrm{m} 2$. The rates of clinical complications increase exponentially with a higher BMI [8].

Much has been studied about the pathophysiology behind obesity and its consequences. Impaired insulin signaling and the downregulation of major insulin-responsive glucose transporters are central to insulin resistance in the obese population. Vascular dysfunction resulting from adipocyte-mediated cytokine release has been implicated in triggering hypertension and dyslipidemia [9]. Despite the strong linkage between elevated BMI and cardiovascular risk factors, numerous reports have suggested favorable cardiovascular outcomes in obese patients as compared to those with normal BMI, which is otherwise referred to as the 'obesity paradox' [10-12]. Different theories, such as body composition, improved cardiorespiratory fitness, greater mobilization of endothelial progenitor cells, decreased thromboxane production, and increased ghrelin sensitivity, have been postulated to explain the improved prognosis in this population. Similar paradoxical results were noted in patients with peripheral arterial disease (PAD); however, this was attributed to excess mortality in the underweight who had a more pronounced history of smoking and obstructive lung disease [13]. Studies analyzing the influence of obesity in PAD outcomes in two equally matched populations while accounting for various confounders are lacking. We conducted a retrospective study to verify the existence of the obesity paradox in patients with PAD in two equally matched cohorts.

\section{Materials And Methods}

\section{Data sources}

The 2016 National Inpatient Sample (NIS), the largest all-payer database of inpatient hospitalization, was used for the study [14]. Initially founded as a component of the Health Care Utilization Project (HCUP) sponsored by the Agency for Healthcare Research and Quality (AHRQ), the NIS is released for public use each year based on the billing data submitted by hospitals to statewide data organizations across the United States (U.S.). Data is collected from 47 states covering almost $97 \%$ of the U.S. population. The NIS approximates a $20 \%$ stratified sample of discharges from all the participating hospitals, comprising over seven million annual hospitalizations. In comparison to the older versions of NIS (before the year 2012), instead of constructing samples from selected hospitals in the US, the newer NIS datasets were created 


\section{Cureus}

utilizing $20 \%$ stratified discharges from all the hospitals in the country. The information of all available hospitalizations is available as deidentified patient demographics, discharge diagnosis as identified by the international classification of diseases, tenth revision clinical modification (ICD-10 CM), procedures performed (ICD-10 PCS), comorbid conditions, discharge status, total charges, and ultimate stay outcome. The dataset allows the identification of one primary discharge diagnosis, and up to 24 secondary discharge diagnoses or comorbidities are available for each hospital stay. The self-weighting design of the newer 2016 model provides a more accurate national estimate compared to the older versions. Since the dataset includes deidentified patient information, permission from the institutional review board was not sought.

\section{Study population and outcomes}

ICD-10-CM codes were used to identify all hospitalizations with a primary discharge diagnosis of PAD. This included patients hospitalized with stable atherosclerosis, chronic ischemia, or critical limb ischemia. All PAD-related admissions were stratified into two groups based on the presence of a secondary diagnosis code: obesity or elevated BMI or both. As discussed above, since multiple studies have shown a poor prognosis in both overweight and obese populations, we used BMI $>25 \mathrm{~kg} / \mathrm{m}^{2}$ as the cut-off to test for the 'obesity paradox.' Two groups comprising $\mathrm{PAD}$ with obesity or $\mathrm{BMI}>25 \mathrm{~kg} / \mathrm{m}^{2}$ and $\mathrm{PAD}$ with $\mathrm{BMI}<25 \mathrm{~kg} / \mathrm{m}^{2}$ were compared to study the primary outcome of in-hospital mortality. Secondary outcomes included the need for intervention, rates of amputation, acute kidney injury, post-catheterization complications, length of stay, and total hospital charges. We defined the need for intervention as those requiring angioplasty (balloon or stent placement) or bypass surgery. PAD-related hospitalization with $\mathrm{BMI}<25 \mathrm{~kg} / \mathrm{m}^{2}$ served as the reference group.

\section{Statistical analysis}

To control for imbalances in the patient and institutional characteristics and mitigate the selection bias, we used a propensity scoring method to establish a matched sample. A propensity score was based on a multivariate logistic regression model that examined the impact of the variables listed in Table 1. Patients with similar propensity scores in the two groups (PAD subjects with and without obesity) were matched using a 1-to-1 scheme without replacement, using an eight to one digit match. All patients were 18 or older. Outcomes were compared between propensity score-matched subjects (PAD subjects with and without obesity). The paired t-test was used for comparisons of continuous variables and the McNemar test for categorical variables in the matched cohorts. All statistical analyses were performed using SAS 9.4 software (SAS Institute Inc., Cary, NC, US).

\begin{tabular}{|c|c|c|c|c|}
\hline \multirow[t]{2}{*}{ Variables } & $\begin{array}{l}\text { With Obesity } \\
(n=41618)\end{array}$ & $\begin{array}{l}\text { Without Obesity } \\
(n=206670)\end{array}$ & $\begin{array}{l}\text { Total } \\
(n=248288)\end{array}$ & P-Value \\
\hline & Mean (SD) & Mean (SD) & Mean (SD) & \\
\hline \multirow{2}{*}{$\begin{array}{l}\text { Age, mean } \pm \text { SD } \\
\text { (years) }\end{array}$} & $66.8(11.9)$ & 72.3 (11.9) & 71.4 (11.9) & $<0.0001$ \\
\hline & $\mathrm{N}(\%)$ & N (\%) & N (\%) & \\
\hline \multicolumn{5}{|l|}{ Gender } \\
\hline Female & 19535 (46.9\%) & $87111(42.1 \%)$ & $106646(43.0 \%)$ & $<0.0001$ \\
\hline Male & 22058 (53.0\%) & $119486(57.8 \%)$ & $141544(57.0 \%)$ & \\
\hline
\end{tabular}




\section{Cureus}

\begin{tabular}{|c|c|c|c|c|}
\hline $\begin{array}{l}\text { Race } \\
\text { Variables } \\
\text { White }\end{array}$ & $\begin{array}{l}\text { With Obesity } \\
(n=41618) \\
30459(73.2 \%)\end{array}$ & $\begin{array}{l}\text { Without Obesity } \\
(n=206670) \\
153310(74.2 \%)\end{array}$ & $\begin{array}{l}\text { Total } \\
(n=248288) \\
183769(74.0 \%)\end{array}$ & $\begin{array}{c}\text { P-Value } \\
<0.0001\end{array}$ \\
\hline Black & 68甲4(16.4\%) & 30499 (\$4.4\%) & 39ean (\$5D.d\%) & \\
\hline Hispanic & $3176(7.6 \%)$ & $14972(7.2 \%)$ & $18148(7.3 \%)$ & \\
\hline Asian or Pacific Islander & $297(0.7 \%)$ & $2747(1.3 \%)$ & $3044(1.2 \%)$ & \\
\hline Native American & $206(0.5 \%)$ & $1026(0.5 \%)$ & $1232(0.5 \%)$ & \\
\hline Other & $666(1.6 \%)$ & $4130(2.0 \%)$ & $4796(1.9 \%)$ & \\
\hline \multicolumn{5}{|l|}{ Household income } \\
\hline$\$ 1-24,999$ & $14320(34.4 \%)$ & $68585(33.2 \%)$ & 82905 (33.4\%) & $<0.0001$ \\
\hline$\$ 25,000-34,999$ & $11492(27.6 \%)$ & $54679(26.5 \%)$ & $66171(26.7 \%)$ & \\
\hline$\$ 35,000-44,999$ & $9490(22.8 \%)$ & 47880 (23.2\%) & $57370(23.1 \%)$ & \\
\hline 45,000 or more & $6312(15.2 \%)$ & $35511(17.2 \%)$ & $41823(16.8 \%)$ & \\
\hline Comorbidities & $\mathrm{N}(\%)$ & $\mathrm{N}(\%)$ & $\mathrm{N}(\%)$ & \\
\hline Smoking & $6962(16.7 \%)$ & $44201(21.4 \%)$ & $51163(20.6 \%)$ & $<0.0001$ \\
\hline Coronary Artery Disease & $23025(55.3 \%)$ & 115902 (56.1\%) & $138927(56.0 \%)$ & 0.0046 \\
\hline $\begin{array}{l}\text { Congestive Heart } \\
\text { Failure }\end{array}$ & $5527(13.3 \%)$ & $23017(11.1 \%)$ & 28544 (11.5\%) & $<0.0001$ \\
\hline Chronic Kidney Disease & $18643(44.8 \%)$ & $78386(37.9 \%)$ & $97029(39.1 \%)$ & $<0.0001$ \\
\hline Diabetes Mellitus & $27769(66.7 \%)$ & $92925(45.0 \%)$ & $120694(48.6 \%)$ & $<0.0001$ \\
\hline Hypertension & $18038(43.3 \%)$ & $97601(47.2 \%)$ & $115639(46.6 \%)$ & $<0.0001$ \\
\hline
\end{tabular}

TABLE 1: Comparison of demographics and comorbidities in patients with peripheral arterial disease with and without obesity (before propensity match).

$\mathrm{SD}=$ standard deviation

\section{Results}

A total of 248,228 admissions with a primary discharge diagnosis of PAD were identified, of which 41,618 (16.76\%) had a secondary discharge diagnosis of obesity or BMI greater than 25 $\mathrm{kg} / \mathrm{m}^{2}$. Table 1 demonstrates the baseline characteristics of both groups before matching propensity scores. The mean age of patients in the obesity group was lower as compared to nonobese patients (66.8 vs. 72.3, p<0.0001). As was pointed out in previous studies, the rates of smoking were higher in patients with $\mathrm{BMI}<25 \mathrm{~kg} / \mathrm{m}^{2}$ when compared to patients with $\mathrm{BMI}>25$ $\mathrm{kg} / \mathrm{m}^{2}$ (21.4\% vs. 16.7\%, p<0.0001). Higher BMI was also associated with concomitant secondary diagnosis of congestive heart failure (13.3\% vs $11.1 \%$, $\mathrm{p}<0.0001)$, chronic kidney disease $(44.8 \%$ vs $37.9 \%$, $\mathrm{p}<0.0001)$, and diabetes mellitus (66.7\% vs $45.0 \%$, $\mathrm{p}<0.0001)$. 


\section{Cureus}

After calculating propensity scores; matching both cohorts and accounting for missing information, we compared 41,589 (16.75\%) PAD admissions with elevated BMI (BMI>25 kg/m²) or secondary diagnosis of obesity to a similar number of hospitalizations in the reference group. In the obesity group, 4356 (10.47\%) had BMI between 25 to $29.9 \mathrm{~kg} / \mathrm{m}^{2}, 7195$ (17.30\%) had BMI between 30.0 to $34.9 \mathrm{~kg} / \mathrm{m}^{2}$, 9505 (22.85\%) had BMI between 35.0 to $39.9 \mathrm{~kg} / \mathrm{m}^{2}$, and 12522 (30.11\%) admissions had BMI $>40 \mathrm{~kg} / \mathrm{m}^{2}$. A total of 8011 admissions (19.26\%) had secondary discharge diagnosis of overweight, obesity, or morbid obesity; however, the BMI range was not specified. Table 2 compares baseline characteristics between both groups after calculating propensity scores. After propensity matching, the standardized mean difference between both groups was less than $5 \%$. The mean age of the cohort after matching was $66.9 \pm 11.7$ years. In the obesity group, $53 \%$ were males and $46 \%$ were females as compared to $54.6 \%$ males and $45.4 \%$ females in the non-obese group. The pre-match confounding effect of smoking was negated post-match, and the rates for both groups were $16.7 \%$ vs. $17.0 \%$.

\begin{tabular}{|c|c|c|c|c|}
\hline \multirow[t]{2}{*}{ Variables } & $\begin{array}{l}\text { With Obesity } \\
(n=41589)\end{array}$ & $\begin{array}{l}\text { Without } \\
\text { Obesity }(n=41589)\end{array}$ & $\begin{array}{l}\text { Total } \\
(n=83178)\end{array}$ & $\begin{array}{l}\text { Standardized mean } \\
\text { Differences }\end{array}$ \\
\hline & Mean (SD) & Mean (SD) & Mean (SD) & \\
\hline \multirow{2}{*}{$\begin{array}{l}\text { Age, mean } \pm \text { SD } \\
\text { (years) }\end{array}$} & $66.8(11.9)$ & $66.9(11.5)$ & $66.9(11.7)$ & -0.12 \\
\hline & $\mathrm{N}(\%)$ & N(\%) & $\mathrm{N}(\%)$ & \\
\hline \multicolumn{5}{|l|}{ Gender } \\
\hline Female & $19533(47.0 \%)$ & $18861(45.4 \%)$ & 38394 (46.2\%) & 3.2 \\
\hline Male & $22056(53.0 \%)$ & $22728(54.6 \%)$ & $44784(53.8 \%)$ & \\
\hline \multicolumn{5}{|l|}{ Race } \\
\hline White & 30442 (73.2\%) & 30591 (73.6\%) & 61033 (73.4\%) & -0.8 \\
\hline Black & 6803 (16.4\%) & 6884 (16.6\%) & 13687 (16.5\%) & \\
\hline Hispanic & $3175(7.6 \%)$ & 3119 (7.5\%) & 6294 (7.6\%) & \\
\hline $\begin{array}{l}\text { Asian or Pacific } \\
\text { Islander }\end{array}$ & 297 (0.7\%) & $327(0.8 \%)$ & $624(0.8 \%)$ & \\
\hline Native American & $206(0.5 \%)$ & $163(0.4 \%)$ & 369 (0.4\%) & \\
\hline Other & $666(1.6 \%)$ & $505(1.2 \%)$ & $1171(1.4 \%)$ & \\
\hline \multicolumn{5}{|l|}{ Household income } \\
\hline$\$ 1-24,999$ & 14308 (34.4\%) & $14691(35.3 \%)$ & 28999 (34.9\%) & -1.6 \\
\hline$\$ 25,000-34,999$ & $11487(27.6 \%)$ & $11025(26.5 \%)$ & $22512(27.1 \%)$ & \\
\hline$\$ 35,000-44,999$ & 9485 (22.8\%) & 9333 (22.4\%) & $18818(22.6 \%)$ & \\
\hline 45,000 or more & $6309(15.2 \%)$ & 6540 (15.7\%) & $12849(15.4 \%)$ & \\
\hline Comorbidities & N (\%) & N (\%) & N (\%) & \\
\hline
\end{tabular}




\section{Cureus}

\begin{tabular}{|c|c|c|c|c|}
\hline $\begin{array}{l}\text { Smoking } \\
\text { Variables }\end{array}$ & $\begin{array}{l}\text { 6957 (16.7\%) } \\
\text { With Obesity } \\
\text { (n=41589) }\end{array}$ & $\begin{array}{l}\text { 7.270 (17,0\%) } \\
\text { Obesithout }(n=41589)\end{array}$ & $\begin{array}{l}\text { 14027 }(16.9 \%) \\
(n=83178)\end{array}$ & $\begin{array}{l}\text { - } 15 \text { Standardized mean } \\
\text { Differences }\end{array}$ \\
\hline Disease & $\begin{array}{c}23011(55.3 \%) \\
\text { Mean (SD) }\end{array}$ & $\begin{array}{l}23610(56.8 \%) \\
\text { Mean (SD) }\end{array}$ & $\begin{array}{c}46621(56.0 \%) \\
\text { Mean (SD) }\end{array}$ & -2.9 \\
\hline $\begin{array}{l}\text { Congestive Heart } \\
\text { Failure }\end{array}$ & $5526(13.3 \%)$ & $4679(11.3 \%)$ & 10205 (12.3\%) & 2.6 \\
\hline $\begin{array}{l}\text { Chronic Kidney } \\
\text { Disease }\end{array}$ & $18627(44.8 \%)$ & $18384(44.2 \%)$ & $37011(44.5 \%)$ & 1.3 \\
\hline Diabetes Mellitus & $27751(66.7 \%)$ & $28281(68.0 \%)$ & $56032(67.4 \%)$ & -3.1 \\
\hline Hypertension & $18026(43.3 \%)$ & $17491(42.1 \%)$ & 35517 (42.7\%) & 1.7 \\
\hline Propensity Scores & 0.03126 & 0.03126 & NA & 0 \\
\hline
\end{tabular}

\section{TABLE 2: Comparison of demographics and comorbidities in patients with peripheral}

arterial disease after calculating propensity scores.

$\mathrm{SD}=$ standard deviation, $\mathrm{NA}=$ not available.

Before matching both cohorts, the rates of amputation (5.03\% vs 5.0\%, $\mathrm{p}<0.0001)$, need for intervention ( $8.6 \%$ vs $6.4 \%$, $\mathrm{p}<0.0001$ ), and in-hospital mortality ( $3.7 \%$ vs $2.7 \%, \mathrm{p}<0.0001$ ) were lower in PAD hospitalizations with a higher BMI. The rates of acute kidney injury (22.7\% vs $27.4 \%$, $\mathrm{p}$-value $<0.0001)$, and post-catheterization complications ( $0.2 \%$ vs $0.2 \%, \mathrm{p}=0.30074$ ) were higher in the obesity group, however, the post-catheterization complication rates were statistically not significant (Figure 1).

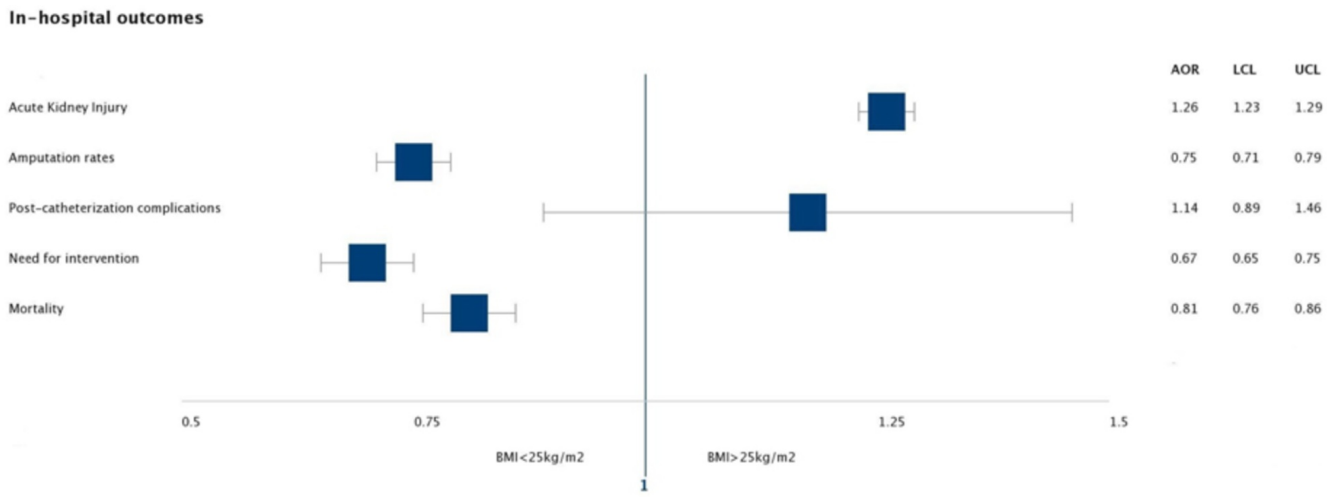

FIGURE 1: Calculated adjusted odds ratio for various inhospital outcomes before calculating propensity scores.

$\mathrm{BMI}=$ Body mass index, $\mathrm{AOR}=$ adjusted odds ratio, $\mathrm{LCL}=$ lower limit of confidence interval, $\mathrm{UCL}=$ Upper limit of confidence interval

Post-matching, lower BMI $\left(<25 \mathrm{~kg} / \mathrm{m}^{2}\right)$ was associated with higher rates of in-hospital mortality (3.30\% vs 2.68\%, p<0.0001), amputation (5.66\% vs 5.30\%, p<0.0001), and need for intervention 


\section{Cureus}

(9.44\% vs $6.42 \%$, $\mathrm{p}<0.0001)$. On the contrary, patients with higher BMI $\left(>25 \mathrm{~kg} / \mathrm{m}^{2}\right)$ had increased rates of acute kidney injury (AKI) compared to the reference population (27.43\% vs. $22.77 \%, \mathrm{p}<0.0001$ ) (Figures 2-3). All hospitalizations with BMI $>25$ had a higher mean length of stay ( 6.5 days vs. 5.8 days, $\mathrm{p}<0.0001)$ and total hospital charges $(\$ 73,046.17$ vs. $\$ 66,540.94$, $\mathrm{p}<0.0001)$.

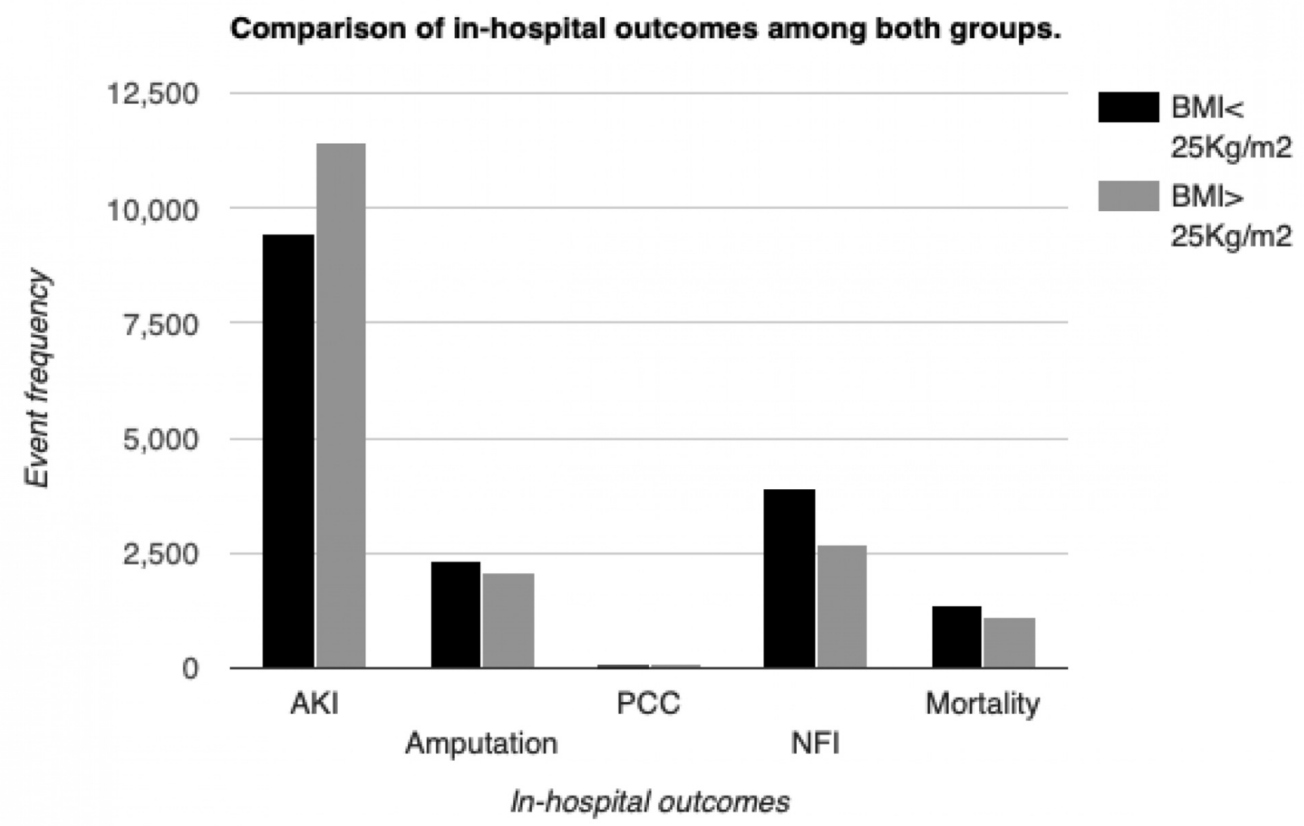

FIGURE 2: Comparison of in-hospital outcomes among both groups after calculating propensity scores. Except PCC, all differences were statistically significant.

PCC=Post-catheterization complications, NFI=Need for intervention

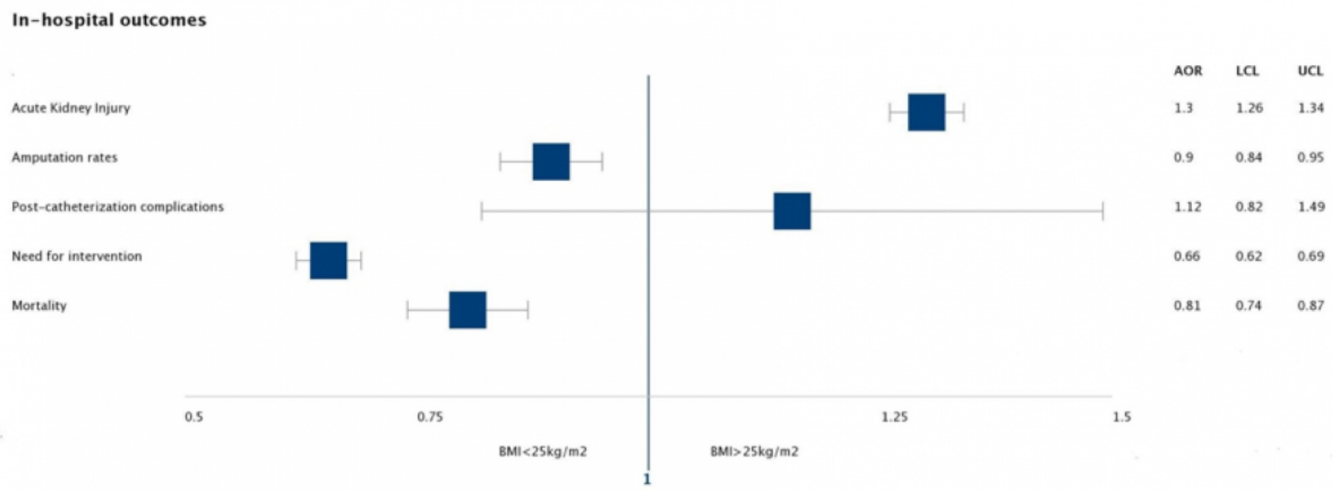

FIGURE 3: Calculated adjusted odds ratio for various inhospital outcomes after calculating propensity scores.

$\mathrm{BMI}=$ Body mass index, $\mathrm{AOR}=$ adjusted odds ratio, $\mathrm{LCL}=$ lower limit of confidence interval, $U C L=U p p e r$ limit of confidence interval 


\section{Discussion}

The overall prevalence of PAD increases substantially from 3\%-10\% to $15 \%-20 \%$ after the age of 70years [15]. The prognosis of PAD is significantly worse in diabetes, end-stage renal disease, and active smokers. In our retrospective study, we observed an inverse relationship between obesity and mortality in patients with PAD, consistent with the findings of the 'obesity paradox,' as described previously in the literature. The results in previous studies, however, were not reproducible once adjusted for smoking and COPD [13]. To the best of our knowledge, this is the largest observational study where one to one matching was performed, and findings were tested before and after the application of propensity scores. In our study, the presence of a higher BMI independently decreased the odds of in-hospital mortality by $19 \%$ in patients with PAD. Uretsky et al. studied the long-term outcomes of obesity in patients with hypertension and found a 30\% lower all-cause mortality in overweight and obese population despite less effective blood pressure control in this population [16].

A similar contradictory role of obesity has also been reported with heart failure. Obesity increases cardiac output, cardiac workload, and filling pressures, cumulating increasing the risk of heart failure. Despite the known adverse effects of the obese state on cardiovascular hemodynamics, the overall prognosis tends to be superior in this population [17-18]. A metaanalysis conducted by Oreopoulus et al. showed a $19 \%$ and $40 \%$ cardiovascular mortality benefit in the overweight and obese populations, respectively [19]. The exact pathophysiology behind this phenomenon remains elusive. Excess adipose tissue produces soluble tumor necrosis factor receptor, which plays a protective role by neutralizing the toxic effects of tumor necrosis factoralpha [20]. Higher metabolic reserve and attenuation of the sympathetic and renin-angiotensin systems all seem to favor better outcomes in the obese population.

Nehler MR et al. reported the mean annualized prevalence of critical limb ischemia (CLI) around $1.33 \%$. The same study estimated the progression of PAD to CLI in $11.08 \%$ of cases [21]. The prevalence seems to be higher in diabetics; however, similar studies based on BMI are lacking [22]. In our study, the prevalence of CLI was higher in patients with BMI $<25 \mathrm{~kg} / \mathrm{m}^{2}$. The prevalence of CLI in the propensity-matched cohort was $7.93 \%$ in patients with BMI $<25$

$\mathrm{kg} / \mathrm{m}^{2}$ as compared to $5.17 \%$ in those with higher BMI. This raises the possibility of CLI being one of the driving factors associated with poorer PAD outcomes in patients with low to normal BMI. CLI, the most severe presentation of PAD, is characterized by multisegmental blood flow impairment with ischemic rest pain, ulceration, or gangrenous formation. CLI is associated with high amputation rates and worse mortality outcomes, especially in elderly and diabetic patients [23]. The initial mortality rate of $20 \%$ within six months of diagnosis can rise to $50 \%$ at the end of five years [23]. The amputation rates for CLI is estimated to be somewhere between $10 \%$ and $40 \%$ at six months [24].

The underlying pathophysiology behind coronary artery disease and PAD include atherosclerotic plaque formation, resulting in compromised blood flow. Traditional cardiovascular risk factors, such as age, smoking, hypertension, and obesity, have all been implicated in the progression of both conditions [25]. Despite this, several studies have shown the obesity survival paradox, highlighting an association between higher BMI and survival [1012] The role of obesity in PAD outcomes is also not well-established. While some studies have shown clear survival benefits [13,26], other studies have failed to show similar results [26]. Various theories explaining this phenomenon have been cited in the literature. Obese patients are more likely to seek medical care at an earlier stage given other comorbid conditions potentially influencing long-term outcomes, more aggressive treatment, and medication compliance in this population. High suspicion and better screening have reduced the time to 
diagnosis drastically. The presence of occult malignancy and COPD have also been cited as potential explanations for poor outcomes in the underweight [13]. Obesity serves as a nutritional reserve against cardiac cachexia, which is particularly important in older patients, as it carries a poor prognosis. The detrimental effects of obesity have also been attributed to concomitant inflammation, as favorable outcomes have been noted in the obese, with low levels of the inflammatory marker; while, on the other hand, obesity with elevated inflammatory markers tends to have worse consequences [27].

More recently, the role of BMI as an assessment tool for obesity or cardiovascular risk factor has come under scrutiny [28]. The limitation of BMI in differentiating excess body fat from lean body mass has been well-established [29]. Better outcomes in patients with a higher BMI but a predominant lean body mass has also been attributed as a contributing factor explaining the obesity paradox. Studies using the abdominal circumference and waist-to-hip ratio have gained attention due to the above-mentioned limitations of BMI. Studies using fat percentage along with BMI have also shown similar paradoxical results [30]. Despite this, purposeful weight loss has been associated with better exercise capacity, inflammation, and lipid profile [30]. Based on our results, a higher BMI is associated with a better prognosis after adjusting for age, sex, and other comorbidities. Despite the paradox, the author recommends purposeful long-term weight loss to improve obesity-related morbidity.

The following limitations should be considered when interpreting the findings of our study. First, since the NIS database relies heavily on ICD-10-CM diagnosis codes, any error in coding can affect the validity of the study. Second, we were unable to assess the medical compliance of the patients leading to the hospitalization. The comparison of obese patients being medically more compliant or vice versa compared to those with low or normal BMI could not be established. We were unable to clarify whether those with ICD codes for tobacco use were active or former smokers and, if so, the extent of smoking was not quantified. We lacked data on outof-hospital long-term outcomes in these patients. The present study also had its strength in being the largest retrospective observational study testing obesity paradox in propensitymatched cohorts accounting for numerous confounders among patients admitted with PAD.

\section{Conclusions}

We found the prognosis of PAD was inversely proportional to the BMI status of the patient. Various theories have been postulated explaining this phenomenon and questioning the utility of BMI as an indicator of body fat. Future studies looking further into the pathophysiology and consistency of these results with other obesity indices are needed.

\section{Additional Information Disclosures}

Human subjects: All authors have confirmed that this study did not involve human participants or tissue. Animal subjects: All authors have confirmed that this study did not involve animal subjects or tissue. Conflicts of interest: In compliance with the ICMJE uniform disclosure form, all authors declare the following: Payment/services info: All authors have declared that no financial support was received from any organization for the submitted work. Financial relationships: All authors have declared that they have no financial relationships at present or within the previous three years with any organizations that might have an interest in the submitted work. Other relationships: All authors have declared that there are no other relationships or activities that could appear to have influenced the submitted work.

\section{References}

1. Obesity: Preventing and Managing the Global Epidemic. Report of a WHO Consultation . World 
Health Organization, Geneva; 2000.

2. Berrington de Gonzalez A, Hartge P, Cerhan JR, et al.: Body-mass index and mortality among 1.46 million white adults. N Engl J Med. 2010, 363:2211-2219. 10.1056/NEJMoa1000367

3. Global BMI Mortality Collaboration, Di Angelantonio E, Bhupathiraju SN, et al.: Body-mass index and all-cause mortality: individual-participant-data meta-analysis of 239 prospective studies in four continents. Lancet. 2016, 8:776-786. 10.1016/S0140-6736(16)30175-1

4. Olshansky SJ, Passaro DJ, Hershow RC, et al.: A potential decline in life expectancy in the United States in the 21st century. N Engl J Med. 2005, 352:1138-1145. 10.1056/NEJMsr043743

5. Nguyen NT, Nguyen XM, Lane J, Wang P: Relationship between obesity and diabetes in a US adult population: findings from the National Health and Nutrition Examination Survey, 19992006. Obes Surg. 2011, 21:351-355. 10.1007/s11695-010-0335-4

6. Poirier P, Giles TD, Bray GA, Hong Y, Stern JS, Pi-Sunyer FX, Eckel RH: Obesity and cardiovascular disease: pathophysiology, evaluation, and effect of weight loss. Arterioscler Thromb Vasc Biol. 2006, 26:968-976. 10.1161/CIRCULATIONAHA.106.171016

7. Aune D, Sen A, Norat T, Janszky I, Romundstad P, Tonstad S, Vatten LJ: Body mass index, abdominal fatness, and heart failure incidence and mortality: a systematic review and doseresponse meta-analysis of prospective studies. Circulation. 2016, 16:639-649.

10.1161/CIRCULATIONAHA.115.016801

8. Flegal KM, Graubard BI, Williamson DF, Gail MH: Excess deaths associated with underweight, overweight, and obesity. JAMA. 2005, 293:1861-1867.

9. Redinger RN: The pathophysiology of obesity and its clinical manifestations . Gastroenterol Hepatol (N Y). 2007, 3:856-863.

10. Elagizi A, Kachur S, Lavie CJ, Carbone S, Pandey A, Ortegad FB, Milania RV: An overview and update on obesity and the obesity paradox in cardiovascular diseases. Prog Cardiovasc Dis. 2018, 61:142-150.

11. Hainer V, Aldhoon-Hainerová I: Obesity paradox does exist. Diabetes Care. 2013, 2:276-281.

12. Horwich TB, Fonarow GC, Clark AL: Obesity and the obesity paradox in heart failure. Prog Cardiovasc Dis. 2018, 61:151-156. 10.1016/j.pcad.2013.10.004

13. Galal W, van Gestel YRBM, Hoeks SE, et al.: The obesity paradox in patients with peripheral arterial disease. Chest. 2008, 134:925-930. 10.1378/chest.08-0418

14. HCUP-NIS. Healthcare Cost and Utilization Project (HCUP) databases . (2018). Accessed: May 21, 2019: https://www.hcup-us.ahrq.gov/nisoverview.jsp.

15. Dua A, Lee CJ: Epidemiology of peripheral arterial disease and critical limb ischemia . Tech Vasc Interv Radiol. 2016, 19:91-95. 10.1053/j.tvir.2016.04.001

16. Uretsky S, Messerli FH, Bangalore S, Champion A, Cooper-DeHoff RM, Zhou Q, Pepine CJ: Obesity paradox in patients with hypertension and coronary artery disease . Am J Med. 2007, 120:863-870. 10.1016/j.amjmed.2007.05.011

17. Lavie CJ, Osman AF, Milani RV, Mehra MR: Body composition and prognosis in chronic systolic heart failure: the obesity paradox. Am J Cardiol. 2003, 91:891-894. 10.1016/S00029149(03)00031-6

18. Horwich TB, Fonarow GC, Hamilton MA, MacLellan WR, Woo MA, Tillisch JH: The relationship between obesity and mortality in patients with heart failure. J Am Coll Cardiol. 2001, 38:789-795. 10.1016/S0735-1097(01)01448-6

19. Oreopoulos A, Padwal R, Kalantar-Zadeh K, Fonarow GC, Norris CM, McAlister FA: Body mass index and mortality in heart failure: a meta-analysis. Am Heart J. 2008, 156:13-22. 10.1016/j.ahj.2008.02.014

20. Mohamed-Ali V, Goodrick S, Bulmer K, Holly JMP, Yudkin JS, Coppack SW: Production of soluble tumor necrosis factor receptors by human subcutaneous adipose tissue in vivo. Am J Physiol. 1999, 277:E971-E975. 10.1152/ajpendo.1999.277.6.E971

21. Nehler MR, Duval S, Diao L, et al.: Epidemiology of peripheral arterial disease and critical limb ischemia in an insured national population. J Vasc Surg. 2014, 60:686-695.

10.1016/j.jvs.2014.03.290

22. Joosten MM, Pai JK, Bertoia ML, Rimm EB, Spiegelman D, Mittleman MA, Mukamal KJ: Associations between conventional cardiovascular risk factors and risk of peripheral artery disease in men. JAMA. 2012, 308:1660-1667. 10.1001/jama.2012.13415

23. Uccioli L, Meloni M, Izzo V, Giurato L, Merolla S, Gandini R: Critical limb ischemia: current challenges and future prospects. Vasc Health Risk Manag. 2018, 26:63-74.

10.2147/VHRM.S125065 
24. Norgren L, Hiatt WR, Dormandy JA, Nehler MR, Harris KA, Fowkes FG: Intersociety consensus for the management of peripheral arterial disease (TASC II). J Vasc Surg. 2007, 45:5-67. 10.1016/j.jvs.2006.12.037

25. Giugliano G, Brevetti G, Laurenzano E, Brevetti L, Luciano R, Chiariello M: The prognostic impact of general and abdominal obesity in peripheral arterial disease. Int J Obes. 2010, 34:280-6.

26. Golledge J, Cronin O, Iyer V, Bradshaw B, Moxon JV, Cunningham MA: Body mass index is inversely associated with mortality in patients with peripheral vascular disease.

Atherosclerosis. 2013, 229:549-555. 10.1016/j.atherosclerosis.2013.04.030

27. Drechsler C, Wanner C: The obesity paradox and the role of inflammation. J Am Soc Nephrol. 2015, 27:1270-1272. 10.1681/ASN.2015101116

28. Lavie CJ, De Schutter A, Milani RV: Body composition and the obesity paradox in coronary heart disease: can heavier really be healthier?. Heart. 2015, 101:1610-1611. 10.1136/heartjnl2015-307966

29. Azimi A, Charlot MG, Torp-Pedersen C, et al.: Moderate overweight is beneficial and severe obesity detrimental for patients with documented atherosclerotic heart disease. Heart. 2013, 99:655-660. 10.1136/heartjnl-2012-303066

30. Lavie CJ, Milani RV, Artham SM, Patel DA, Ventura HO: The obesity paradox, weight loss, and coronary disease. Am J Med. 2009, 122:1106-1114. 10.1016/j.amjmed.2009.06.006 